\title{
High-throughput mutation, selection, and phenotype screening of mutant methanogenic archaea
}

Mary E. Walter ${ }^{1}$, Alicia Ortiz ${ }^{1}$, Casey Sondgeroth ${ }^{1}$, Nathan M. Sindt ${ }^{1}$, Nikolas Duszenko ${ }^{1}$, Jennie L. Catlett ${ }^{1}$, You Zhou ${ }^{2}$, Shah Valloppilly ${ }^{3}$, Christopher Anderson ${ }^{4}$, Samodha Fernando $^{5}$, Nicole R. Buan ${ }^{1 *}$

${ }^{1}$ Redox Biology Center, Department of Biochemistry, University of Nebraska-Lincoln, N200 Beadle Center, Lincoln, NE 68588-0664

${ }^{2}$ Morrison Microscopy Core Research Facility, Center for Biotechnology, University of Nebraska-Lincoln, E117 Beadle Center, Lincoln, NE 68588-0664

${ }^{3}$ Nebraska Center for Materials and Nanoscience, University of Nebraska-Lincoln, 855 N 16th St, Lincoln, NE 68588

${ }^{4}$ School of Biological Sciences, University of Nebraska, Lincoln, NE 68588

${ }^{5}$ Department of Animal Science, University of Nebraska-Lincoln, C220K Animal Science, Lincoln, NE 68583

*To whom correspondence should be addressed: (nbuan2@unl.edu) 


\section{Abstract}

Bacterial and archaeal genomes can contain $30 \%$ or more hypothetical genes with no predicted function. Phylogenetically deep-branching microbes, such as methane-producing archaea (methanogens), contain up to $50 \%$ genes with unknown function. In order to formulate hypotheses about the function of hypothetical gene functions in the strict anaerobe, Methanosarcina acetivorans, we have developed high-throughput anaerobic techniques to UV mutagenize, screen, and select for mutant strains in 96-well plates. Using these approaches we have isolated 10 mutant strains that exhibit a variety of physiological changes including increased or decreased growth rate relative to the parent strain when cells use methanol and/or acetate as carbon and energy sources. This method provides an avenue for the first step in identifying new gene functions: associating a genetic mutation with a reproducible phenotype. Mutations in bona fide methanogenesis genes such as corrinoid methyltransferases and proton-translocating $\mathrm{F}_{420} \mathrm{H}_{2}$ :methanophenazine oxidoreductase (Fpo) were also generated, opening the door to in vivo functional complementation experiments. Irradiation-based mutagenesis such as from ultraviolet (UV) light, combined with modern genome sequencing, is a useful procedure to discern systems-level gene function in prokaryote taxa that can be axenically cultured but which may be resistant to chemical mutagens.

\section{Keywords}

methanogen, Methanosarcina, struvite, archaea, methane

\section{Abbreviations}

2D, two-dimensional; DMS, dimethylsulfide; DNA, deoxyribonucleic acid; $\mathrm{MeOH}$, methanol; MT, methanethiol; ORFs, open reading frames; TMA, trimethylamine; UV, ultraviolet. 


\section{Introduction}

Reverse-genetics, the ability to make site-directed mutations in an organism's genome, is the goldstandard for genetic experiments to assess the role of a gene on cell physiology. However, many organisms do not have genetic systems, either because they cannot be cultured easily in the laboratory, because they have robust restriction modification systems that degrade foreign DNA, or because they have formidable structural barriers (cell walls or S-layers) that prevent entry of foreign DNA. Classical forward genetics, using ultraviolet (UV) or chemically induced random mutagenesis and selecting or screening for a desired growth phenotype, has advantages in that the experimenter does not already need a gene identity or a genetic system. Combined with modern advances in genome sequencing technology, UV mutagenesis and phenotype selection/screens may be the technical approach that unlocks the metabolic secrets of microbes which lack genetic systems (1-5).

We have developed several techniques to facilitate high-throughput genetic selections and screens in the strict anaerobe, Methanosarcina acetivorans. M. acetivorans is a methane-producing archaeon (methanogen). It grows by reducing methanol, methylamines, methylsulfides, carbon monoxide, or acetate to methane gas (6). M. acetivorans has the largest methanogen genome sequenced to date, and the chromosome contains a high percentage of unknown genes (7). Because methanogens are distantly related to other model organisms like E. coli, up to $53 \%$ of the predicted open reading frames (ORFs) in M. acetivorans have unknown function (8).

M. acetivorans can use several carbon sources to grow. Therefore, it is possible to mutate genes needed to grow on one carbon source but not on the others. M. acetivorans is also fully prototrophic, although supplementation of the medium with defined vitamins increases the growth rate and biomass yield of cultures (data not shown). On the other hand, addition of yeast extract to culture medium can inhibit growth for unknown reasons. The ability to generate and screen large numbers of mutant strains would be valuable for identifying other genes that play a role in methanogenesis, and in defining novel vitamin transport, scavenging, and toxicity pathways. We investigated whether we could develop a UV mutagenesis and high-throughput method to detect previously uncharacterized genes that are involved in methanogenesis from either acetate or methanol.

Though $M$. acetivorans has a reasonably well developed genetic system, the unbiased nature of UV mutagenesis and a classical phenotype selection or screen is invaluable because it will allow us to 1) define gene functions of the many unknown and hypothetical genes, 2) identify transcriptional or post- 
translational regulators which may themselves be constitutively expressed, 3 ) isolate point mutations that can inform about enzyme mechanism and/or structure, and 4) identify genes which may be involved in a given biochemical pathway that we would not have predicted (9).

Using UV mutagenesis and classical phenotype screening requires high numbers of colonies on the order of several thousand for saturation mutagenesis. The high numbers of colonies that must be screened to find mutants with a desired phenotype represents a technical hurdle when studying relatively slowgrowing, strict anaerobes like M. acetivorans. For instance, classical screens in E. coli require several hundred petri dishes, which will take up significant bench and incubator space. However, strict anaerobes must be grown under oxygen-free conditions, and all experimental steps, including incubation of petri plates, and growth curve measurements, must be kept anaerobic (10). Our techniques for high-throughput genetic screening of $M$. acetivorans use a 96-well plate format (Figure 1).

Figure 1. Workflow for high-throughput UV mutagenesis and phenotype screening of methanogens.

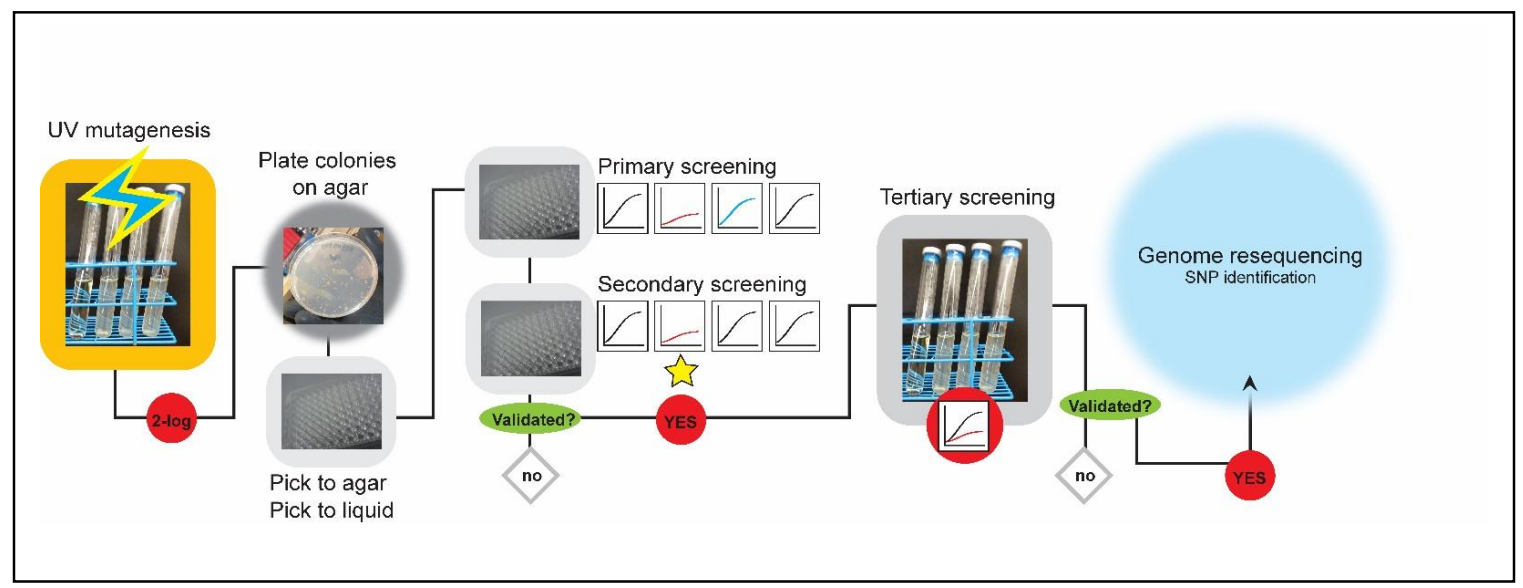

Although a recent paper describes the clever use of canning jars fitted with rubber gaskets to grow Methanosarcina in 96-well plates, specialized anaerobic equipment is necessary to grow hundreds of petri dishes and 96-well plates necessary for high-throughput genetic screening (11). We have put two Wolfe incubators in our anaerobic chamber for growth of up to 306 petri dishes or 96 -well plates. The Wolfe incubators are controlled by a gas manifold, allowing the growth of Methanosarcina under controlled atmosphere using premixed gases. Assembly of the anaerobic chamber and Wolfe incubators has been previously described (10). Here, we detail our current methods using this equipment for UV 
mutagenizing $M$. acetivorans and phenotype screening on agar and in liquid medium in 96-well plates. We also describe the growth phenotypes of 10 mutant strains generated using these procedures.

\section{Materials and Methods}

Growth of M. acetivorans. Methanosarcina strains (Table 1) were grown under strictly anaerobic conditions in HS mineral salts medium $(12,13)$. For growth on solid medium, cells were plated on HS medium containing $1.4 \%$ agar $(\mathrm{w} / \mathrm{v}$ ) with the appropriate carbon source and additions as previously described (10). The following anaerobic additions were added when appropriate: methanol (MeOH, 125 $\mathrm{mM})$, acetate $(120 \mathrm{mM})$, methanol + acetate $(125 \mathrm{mM} \mathrm{MeOH}+40 \mathrm{mM}$ acetate), trimethylamine (TMA, $50 \mathrm{mM})$, puromycin $(2 \mu \mathrm{g} / \mathrm{ml})$.

\section{Table 1. Strains described in this study}

\begin{tabular}{|c|c|c|}
\hline NB\# & Phenotype & Reference \\
\hline 34 & Parent $(\Delta h p t:: \phi C 31$ int, attP) & (13) \\
\hline 89 & $\begin{array}{l}\text { Slow growth on methanol or methanol + acetate. Struvite } \\
\text { crystals on acetate. }\end{array}$ & This study \\
\hline 90 & Slow growth on methanol. Struvite crystals on acetate. & This study \\
\hline 91 & $\begin{array}{l}\text { Fast growth on methanol or methanol + acetate. Struvite } \\
\text { crystals on acetate. }\end{array}$ & This study \\
\hline 92 & $\begin{array}{l}\text { Slow growth on methanol. Struvite crystals on acetate. } \\
\text { Struvite crystals on acetate. }\end{array}$ & This study \\
\hline 93 & Slow growth on methanol, methanol + acetate, and acetate. & This study \\
\hline 178 & Slow growth on methanol. & This study \\
\hline 181 & Slow growth on methanol. & This study \\
\hline 193 & Slow growth on methanol. & This study \\
\hline 194 & Slow growth on methanol or methanol + acetate. & This study \\
\hline 195 & Slow growth on methanol. & This study \\
\hline
\end{tabular}

Genome resequencing. Genomic DNA from $1 \mathrm{ml}$ stationary-phase culture was extracted using the Qiagen Blood genomic DNA extraction kit (Qiagen, USA). Sequencing libraries were constructed using the Nextera XT DNA Library Prep Kit (Illumina, Inc.) according to the manufacturer's protocols. Bridge amplification and sequencing with the MiSeq Reagent Kit v3 (Illumina, Inc.) were performed as described by the manufacturer. The resulting sequences were demultiplexed in BaseSapce. Raw data is available under the BioProject accession number PRJNA335646. Adapter and transposon associated sequences and the last $25 \mathrm{bp}$ of the forward read, and the last $100 \mathrm{bp}$ of the reverse read were removed using cutadapt (version 1.8.1).(14) The 'fastq_filter' command in USEARCH (v8.0.1623) was used to remove sequences containing any ambiguous bases, an expected maximum error rate greater than 0.01 , 
and sequences shorter than $100 \mathrm{bp} .(15)$ Only reads where both the forward and reverse read were retained after quality control were used in downstream analysis. The Burrows-Wheeler Alignment tool (BWA) (version 0.7.12) was used to align reads against the reference genome, Methanosarcina acetivorans str. C2A (NC_003552.1).(7, 16) For each mutant strain, a combination of SAMtools, Picard Tools, and BEDTools were used to mark duplicate reads and summarize the read coverage across the reference genome.(17-19) SNPs and indels were identified using the 'mpileup' command (default parameters) in SAMtools.(17)

Microscopy. Crystals from acetate-grown cultures were harvested, placed on $0.2 \mu \mathrm{m}$ filters, and split into three treatment groups; washed twice with $100 \mu \mathrm{L}$ distilled deionized $\mathrm{H}_{2} \mathrm{O}$, washed twice with $70 \%$ ethanol, or washed twice with $0.4 \mathrm{M} \mathrm{NaCl}$ (iso-osmotic with the methanogen growth medium). Crystals were dried at $37^{\circ} \mathrm{C}$ for 48 hours. Crystals were fixed to glass slides with glutaraldehyde, sputter-coated, and observed using a Hitachi S-3000 Variable-Pressure Scanning Electron Microscope.

Powder X-ray Diffraction. Crystals were harvested, washed with $400 \mu \mathrm{L} 0.4 \mathrm{M} \mathrm{NaCl}$, and dried as described above. Dried crystals (0.0155 g) were ground to powder using a glass pestle in a microcentrifuge tube. The unknown powder was analyzed using a Bruker-AXS D8 Discover HighResolution Diffractometer with a General Area Detector Diffraction System (GADDS) at the Nebraska Center for Materials and Nanoscience core facility (NCMN). A highly collimated beam of Cu K $\alpha$ radiation delivered by a combination of Goebel Mirror and $0.5 \mathrm{~mm}$ monocapillary tube was used for the experiment. The powder sample spread on a glass slide was continuously spun to minimize preferred orientation effects in the diffraction intensities. 2D diffraction data (Debye-rings) was collected, while powder sample and the 2D detector were rotated with respected to the incident beam, in 4 frames. With step-wise increment of 25 degrees, 2D diffraction data was obtained in the angular range of $2 \theta \sim 0$ $-95^{\circ}$ and then the data was integrated along the diffraction cone to obtain the $2 \theta$ vs. Intensity pattern as shown in Figure 5E. Culture medium atom composition ( $\mathrm{Na}, \mathrm{Mg}, \mathrm{Ca}, \mathrm{K}, \mathrm{P}, \mathrm{O}, \mathrm{C}, \mathrm{N}, \mathrm{Cl}$ ) was used as a filter when matching the unknown sample data using the ICDD PDF-4+ database. A close match was observed for the entry corresponding to that of the mineral Ammonium Magnesium Phosphate Hydrate, $\left(\mathrm{NH}_{4}\right) \mathrm{Mg}\left(\mathrm{PO}_{4}\right)\left(\mathrm{H}_{2} \mathrm{O}\right)_{6}$, also known as struvite. Furthermore, the structure was confirmed and refined by a detailed powder $x$-ray diffraction profile analysis with a starting model based on ICDD PDF card 04010-2533. Struvite has orthorhombic crystal structure with a spacegroup of Pmn21. Figure 5E illustrates the experimental data, simulation, and the Bragg reflection positions of the refined structure. 
The refined lattice parameters are $a=6.934 \AA, b=6.129 \AA$ and $c=11.198 \AA$. Traces of no other chemical phases were detected in the x-ray diffraction.

\section{Results}

\section{UV mutagenesis to isolate methanogenesis mutants}

UV irradiation is ideal to induce mutations because it is not susceptible to hot-spot mutation bias, as can be observed with transposon or insertion element-induced mutations (20-22). UV light induces thymine dimer formation in DNA, which must be repaired by site excision before chromosomal replication can commence (23). Because different Methanosarcinales species or strains may produce varying amounts of heteropolysaccharide on the outside of the cell, and may have differences in the S-layer permeability, we wanted to avoid using a chemical mutagen (24-35). However, a drawback with UV irradiation is that UV lamp intensities and exposure can vary. To optimize the UV-mutagenesis we generated a UV killing standard curve method to determine the optimal UV exposure time in our experiments (Figure 2A).

Figure 2. Viability counts and growth curves of UV-mutagenized strains. A, UV killing of Methanosarcina in Balch tubes. Exponentially growing cultures were exposed to UV irradiation and diluted to extinction in 96-well plates to determine a killing curve. B and C, Culturess grown on methanol (B) or acetate (C) as energy source.

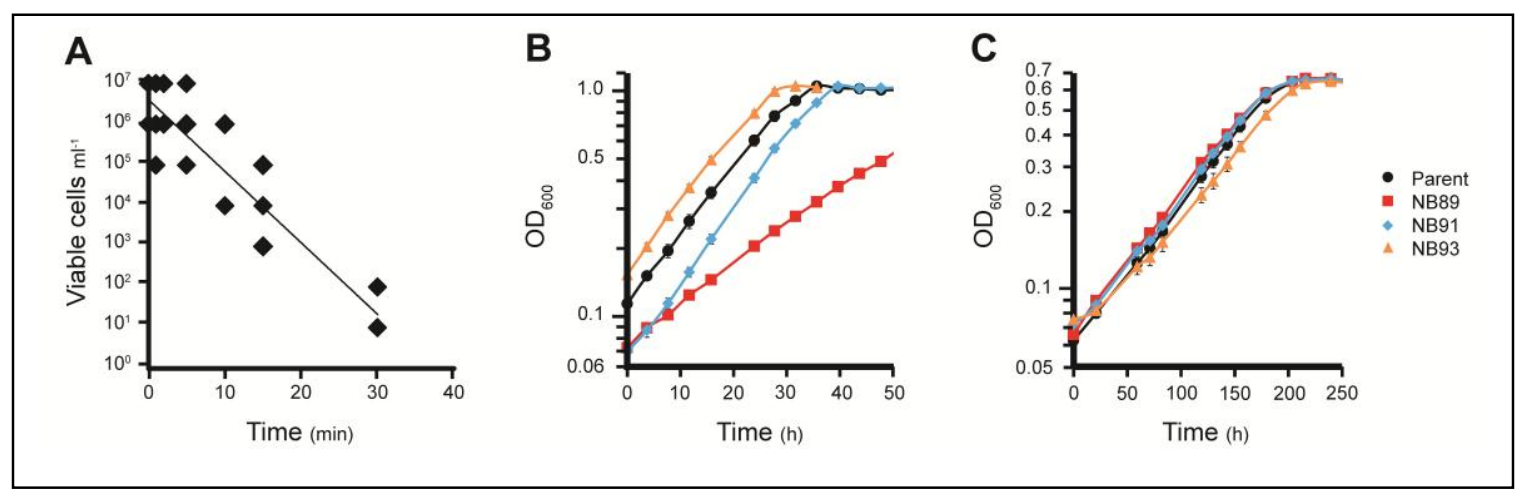

Before UV exposure, $0.5 \mathrm{ml}$ of a recent stationary phase culture was inoculated into fresh Balch tubes containing $10 \mathrm{ml}$ methanol + acetate medium and allowed to grow at $35^{\circ} \mathrm{C}$ overnight to approximately mid-exponential phase. The next morning, the cultures were laid on a UV transilluminator, covered in 
foil, and exposed to UV irradiation for up to 30 minutes. Cultures were then serially 10 -fold diluted to extinction in a 96-well plate in the anaerobic incubator into fresh methanol + acetate medium. The 96well plates were placed in the Wolfe incubator at $35^{\circ} \mathrm{C}$ for 10 days to grow. Plates were scored to determine the number of viable cells per $\mathrm{ml}$ after UV exposure. We determined that 10-15 minutes exposure reliably resulted in approximately 2 -log killing.

\section{Isolation of mutants with increased or decreased growth}

Once the optimal UV mutagenesis conditions were determined, we mutagenized methanol + acetate cultures and plated $100 \mu$ l onto high mineral salt (HS) methanol + acetate agar plates to obtain isolated colonies. Plates were incubated for 14 days to allow visible colonies to develop. Next, 96-well agar plates were filled to $200 \mu \mathrm{l}$ per well with molten agar dispensed from a sterile reagent trough using a serial pipettor. After the agar solidified, individual colonies were picked using sterile sticks and transferred to individual wells, sequentially on a methanol + acetate plate first, onto a methanol plate, and then onto an acetate plate, taking care to keep the same plate coordinates for each colony. Racked, sterile pipette tips were used as a frog to replicate colonies from one 96-well plate to another. Once wells were inoculated, they were placed in the Wolfe incubator to grow at $35^{\circ} \mathrm{C}$. After 2 weeks, plates were compared to identify colonies that appeared to have poor or no growth on one carbon source but not on the other. Cells were then picked using sterile sticks and inoculated into methanol + acetate liquid medium in 96-well plates for secondary screening. Using this method we screened 960 colonies in two weeks. We identified 11 with decreased growth on both acetate and on methanol. 108 mutants had less growth on acetate but wild-type growth on methanol, and 14 mutants had decreased growth on methanol but wild-type growth on acetate (Table 2 ).

Table 2. Mutant screening results

\begin{tabular}{|c|c|c|c|c|c|c|}
\hline Screen & Format & $\begin{array}{l}\text { Number of } \\
\text { strains } \\
\text { screened }\end{array}$ & $\begin{array}{l}\text { Wild-type } \\
\text { growth } \\
\text { phenotype }\end{array}$ & $\begin{array}{l}\text { Reduced } \\
\text { growth } \\
\text { on } \\
\text { acetate }\end{array}$ & $\begin{array}{l}\text { Reduced } \\
\text { growth on } \\
\text { methanol }\end{array}$ & $\begin{array}{l}\text { Reduced } \\
\text { growth on } \\
\text { methanol + } \\
\text { acetate }\end{array}$ \\
\hline Primary screen & 96-well & 960 & 827 & 14 & 108 & 11 \\
\hline $\begin{array}{l}\text { Secondary } \\
\text { screen }\end{array}$ & 96-well & 35 & 25 & 2 & 6 & 2 \\
\hline Tertiary screen & Balch tubes & 11 & 1 & 1 & 9 & 10 \\
\hline
\end{tabular}

\section{Growth curves in 96-well plate format}


Secondary screening in liquid medium in 96-well plate format is advantageous because manual growth curves using a spec20 spectrophotometer is laborious. We identified a large number of primary hits using high-throughput screening on agar plates, and a high-throughput method to screen mutant growth in liquid cultures was desirable. To do this, a 96-well plate reader and computer were set up within the anaerobic chamber. Care should be taken to keep the anaerobic chamber very dry while sensitive electronics are housed in the chamber under $\mathrm{CO}_{2}$ atmosphere. We have been able to keep the plate reader and computer running for at least two years with no discernible effects on performance in our anaerobic chamber.

To screen mutant strains in liquid medium, half the 96 -well plate was filled with $180 \mu \mathrm{l}$ methanol medium, and the other half was filled with $180 \mu \mathrm{l}$ acetate medium. Mutant cultures $(20 \mu \mathrm{l})$ were inoculated into wells of both media in the desired number of biological replicates. Growth in each well was measured automatically using the plate reader at $35^{\circ} \mathrm{C}$ with high shaking intensity at 2 hour intervals for 5 days (growth on methylotrophic substrates) or two weeks (growth on acetate). Using plate reader software, growth curve data was exported to Excel format for analysis.

Using this method we tested a subset of 35 mutant strains that had decreased growth on methanol or acetate. Of the 35 mutants tested, 10 were confirmed to have reproducible growth phenotypes. The mutants fell into two phenotypic classes. Class I were isolates that had decreased growth on methanol, and Class II were those that had decreased growth on acetate.

\section{Tertiary screening in sealed glass Balch culture tubes}

Methanogen medium is often supplemented with sulfide to lower the redox potential (36). Because hydrogen sulfide is volatile, there is a possibility that growth phenotypes may be different when cultures are grown in 96-well plates versus sealed glass Balch tubes. For instance, deletion of the operon encoding CoM-S-S-CoB heterodisulfide reductase, $h d r A B C$, causes the cell to produce methanethiol (MT) or dimethylsulfide (DMS), which diffuses into the headspace (37). In a Balch tube, the MT and DMS eventually reaches a threshold partial pressure that induces expression of dimethylsulfide methyltransferases, and the cell consumes DMS. However, the slow-growth phenotype of the $\triangle h d r A B C$ mutant is exacerbated in a 96-well plate, presumably because the MT and DMS can easily diffuse out of the plate into the bulk gas of the anaerobic chamber (data not shown). 
The 10 strains that passed secondary screening were grown in Balch tubes to determine if their growth phenotypes were specific to the 96-well format. To eliminate experimental variability, the mutants and parental control were grown in biological replicates on the same batch of culture medium. Of the 10 strains, nine had a reproducible phenotype (Table 3). One strain, NB93, had reduced growth rate under all medium conditions tested (growth on methanol, methanol + acetate, and acetate alone). Eight strains had wild-type growth rates on acetate, but decreased growth rate on medium containing methanol or methanol + acetate. One of these strains, NB89, had a severe methanol-specific growth defect that resulted in a $59 \%$ slower growth rate and a $10 \%$ decrease in biomass on methanol but a $20 \%$ decrease in biomass on methanol + acetate. Finally, one strain, NB91, had wild-type growth on acetate, but a $13 \%$ increase in growth rate on methanol and methanol + acetate (Figure 2).

Table 3. Growth rates and maximum culture density in Balch tubes.

\begin{tabular}{|c|c|c|c|c|}
\hline Carbon source & Strain & $\begin{array}{l}\text { Generation } \\
\text { time (h) }\end{array}$ & Std dev & $\begin{array}{l}p \text { value vs } \\
\text { parent }^{1}\end{array}$ \\
\hline \multirow[t]{11}{*}{ Methanol } & Parent & 10.4 & 0.13 & 1 \\
\hline & NB89 & 16.5 & 0.27 & 0.0000016 \\
\hline & NB90 & 10.7 & 0.13 & 0.034 \\
\hline & NB91 & 9.2 & 0.15 & 0.000040 \\
\hline & NB92 & 10.2 & 0.05 & 0.045 \\
\hline & NB93 & 11.1 & 0.17 & 0.0021 \\
\hline & NB178 & 11.1 & 0.37 & 0.041 \\
\hline & NB181 & 11.2 & 0.11 & 0.00017 \\
\hline & NB193 & 12.1 & 0.22 & 0.000099 \\
\hline & NB194 & 12.0 & 0.17 & 0.000022 \\
\hline & NB195 & 11.7 & 0.19 & 0.00012 \\
\hline \multirow[t]{11}{*}{ Methanol + Acetate } & Parent & 10.5 & 0.12 & 1 \\
\hline & NB89 & 20.9 & 3.08 & 0.0099 \\
\hline & NB90 & 11.4 & 1.07 & NS \\
\hline & NB91 & 9.25 & 0.20 & 0.0049 \\
\hline & NB92 & 10.2 & 0.03 & NS \\
\hline & NB93 & 11.8 & 0.58 & 0.023 \\
\hline & NB178 & 12.4 & 1.53 & NS \\
\hline & NB181 & 12.0 & 0.94 & NS \\
\hline & NB193 & 12.9 & 2.03 & NS \\
\hline & NB194 & 13.5 & 1.52 & 0.040 \\
\hline & NB195 & 12.1 & 1.08 & NS \\
\hline \multirow[t]{7}{*}{ Acetate } & Parent & 55.0 & 2.50 & 1 \\
\hline & NB89 & 53.4 & 1.57 & NS \\
\hline & NB90 & 61.9 & 4.38 & NS \\
\hline & NB91 & 57.1 & 3.89 & NS \\
\hline & NB92 & 54.9 & 3.14 & NS \\
\hline & NB93 & 69.1 & 3.11 & 0.0010 \\
\hline & NB178 & 60.9 & 5.14 & NS \\
\hline
\end{tabular}




$\begin{array}{llll}\text { NB181 } & 56.5 & 5.73 & \text { NS } \\ \text { NB193 } & 58.9 & 4.66 & \text { NS } \\ \text { NB194 } & 57.6 & 3.40 & \text { NS } \\ \text { NB195 } & 53.3 & 3.38 & \text { NS }\end{array}$

Calculations are based on growth phenotypes from quadruplicate biological replicates.

${ }^{1} p$ value determined by Student's two-tailed T test $(p<0.05)$.

NS: not significant $(p>0.05)$.

\section{Identification of candidate mutations associated with growth defects}

To determine the effectiveness of UV-induced mutagenesis in M. acetivorans, genomic DNA from the parent strain (NB34) and nine mutants was resequenced and compared to the reference genome (Table S1). (8) As expected, mutations were recovered from all over the chromosome (Figure 3A). Two regions of the chromosome, from 2.8-3.0 $\mathrm{Mb}$ and 5.5-5.7 $\mathrm{Mb}$ accumulated mutations faster than the expected average frequency, and correlated with thymine-rich repeat sequences (Figure 3B). The mean number of mutations per strain was 10 (8 SNPs and 2 Indels) with a median number of 5 mutations (Table S2). On average, $80 \%$ of the mutations were SNPs while $20 \%$ were Indels. The UV mutagenesis method described in this manuscript resulted in a frequency of $1.8 \times 10^{-6}$ mutations per base (Table S3).

Figure 3. Mutations generated by UV irradiation. A, Mutations recovered from the parent strain and eight mutant strains are plotted on the circular genome. B, When the cumulative mutations per site (red) is compared to the mean average cumulative mutations (gray), two mutation hotspots are identified at 2.8-3 $\mathrm{Mb}$ and 5.5-5.7 $\mathrm{Mb}$.

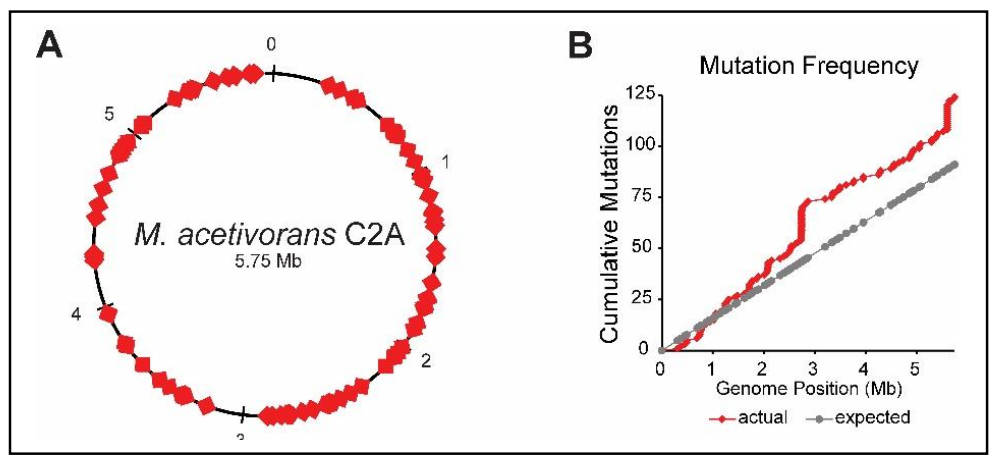

To identify mutations which may be responsible for the observed phenotypes, the resequenced genomes of the NB34 parent and each mutant were compared to the reference $M$. acetivorans genome 
(Figure 4). Sixteen mutations (of 306 total) were found to be in common between all strains. Ten mutations were found in the parent and one or more mutant strains, but seemed to have reverted back to the reference sequence in the remaining strains. Of these mutations, all but one were intergenic regions or genes with hypothetical or unknown function. One mutation, a deletion of a GC at position 5079505 , was in the coding region of $h y p F$, the gene encoding the hydrogenase maturation protein. $M$. acetivorans $\mathrm{C} 2 \mathrm{~A}$ and the parent strain, NB34, do not synthesize functional hydogenases and cannot use hydrogen as an electron donor (6). Due to lack of functional hydrogenase expression in the C2A strain, this deletion can be reasonably expected to have no additional effect on the physiology of NB34 or the mutant strains (38).

Figure 4. Identification of unique mutations in resequenced genomes. The reference $M$. acetivorans genome was compared to the resequenced parent strain and the isolated mutant strains. Most mutations were unique (red circles), but a few were shared by two or more sequenced strains.

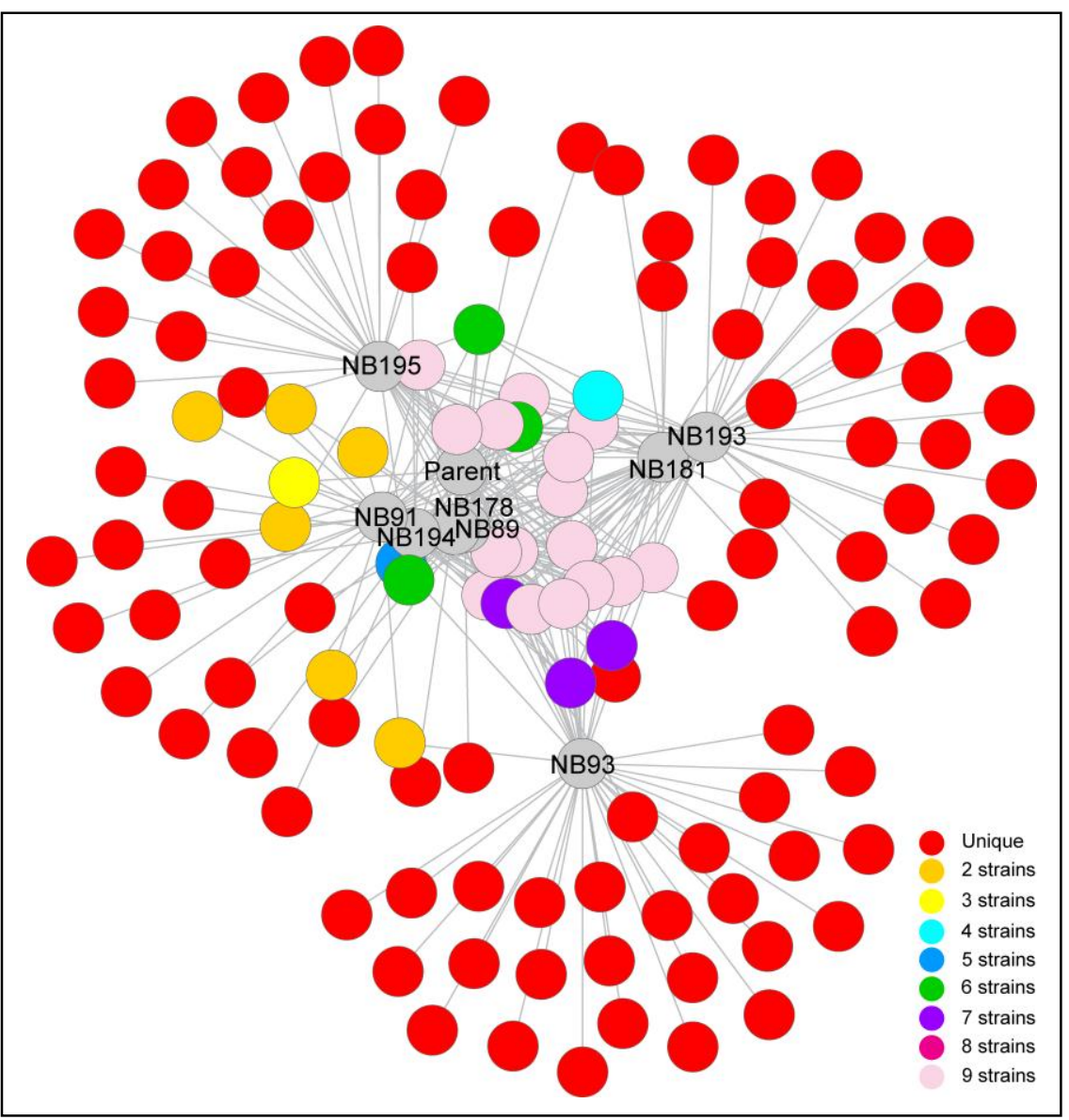


Strain NB89 had the most severe methanol-specific growth defect. Not only was the growth rate slower than the parent strain on methylotrophic substrates, but the final culture density was also affected, suggesting an energetic or a toxicity effect (Table 4).

Table 4. Biomass Measurements

\begin{tabular}{lllll}
\hline Carbon source & Strain & Max OD $_{600}$ & Std dev & $\begin{array}{l}\boldsymbol{p} \text { value vs } \\
\text { parent }^{\mathbf{1}}\end{array}$ \\
\hline Methanol & Parent & 1.05 & 0.008 & 1 \\
& NB89 & 0.94 & 0.005 & 0.0000040 \\
\hline Methanol + Acetate & Parent & 1.03 & 0.030 & 1 \\
& NB89 & 0.82 & 0.050 & 0.0018 \\
\hline Acetate & Parent & 0.67 & 0.01 & 1 \\
& NB89 & 0.68 & 0.01 & NS \\
\hline
\end{tabular}

Calculations are based on growth phenotypes from quadruplicate biological replicates.

${ }^{1} p$ value determined by Student's two-tailed T test $(p<0.05)$.

NS: not significant $(p>0.05)$.

The NB89 genome contained five mutations not found in the parent or in the reference genome (Table 5).

Table 5. Mutations identified in the NB89 genome

\begin{tabular}{|c|c|c|c|c|}
\hline $\begin{array}{l}\text { Genome } \\
\text { position }\end{array}$ & Mutation & Effect & Locus & Predicted function \\
\hline 308383 & C to $\mathrm{T}$ & $\Delta 160-504$ & MA_RS01355 & AAA $^{+}$ATPase \\
\hline 1146094 & $\mathrm{~T}$ to $\mathrm{C}$ & N199D & MA_RS24380 & $\begin{array}{l}\text { PGF } \\
\text { transpeptidase }\end{array}$ \\
\hline 3205790 & A to $G$ & intergenic & (tnp) & none \\
\hline 3753590 & $\triangle$ CTCTGTTGTTAACCCCCTGA & intergenic & $\begin{array}{l}\left(\mathrm{Na}^{+} / \mathrm{H}^{+}\right. \\
\text {antiporter) }\end{array}$ & none \\
\hline 5645793 & $\triangle$ ITGATAGATGACGTTCCCTGTATCTTCTC & $\begin{array}{l}\text { in-frame } \\
\triangle \text { EKIQGTS }\end{array}$ & MA_RS23910 & $\begin{array}{l}\text { formyl transferase } \\
\left(\mathrm{H}_{4} \mathrm{PT} \text { or } \mathrm{tMet}\right)\end{array}$ \\
\hline
\end{tabular}

Three mutations were single base changes, while two were deletions of thymine-rich sequences. Two of the five mutations were in intergenic regions, while three mutations were in predicted protein-coding regions. Based on the genome position and predicted effect, the mutations most likely to contribute to the methanol growth defect are a base substitution at 1146094, an intergenic deletion at position 3753590, and a deletion at position 5645793. The mutation at position 1146094 results in a missense mutation (N199D) in a PGF transpeptidase of unknown function. The mutation at 3753590 results in a deletion $5^{\prime}$ upstream of the $\operatorname{mrpA~Na}{ }^{+} / \mathrm{H}^{+}$antiporter. MrpA has been shown to contribute to growth on 
methanol under low sodium conditions (39). It would seem possible that the 3753590 deletion mutation may have disrupted regulation of $m r p A$ gene expression, somehow affecting growth on methanol but not on acetate. However, the mutagenesis and screening was conducted in medium containing $0.4 \mathrm{M}$ $\mathrm{NaCl}$. Under these conditions (substrate and sodium ion concentrations), the $\Delta m r p A$ mutant displayed wild-type growth (39). Therefore the mutation at 3753590 in strain NB89 is unlikely to be the cause of the slow growth phenotype on methanol. Finally, the 5645793 mutation causes an in-frame deletion of residues 74-80 (EKIQGTS) in a predicted formyl transferase of unknown function (locus MA_RS23910). Overall the predicted polypeptide is 87 amino acid residues in length and $10.1 \mathrm{kDa}$. The deleted residues in the NB89 mutants strain lie just outside the formyltransferase core domain residues 2-68. Nearby on the genome are two methionyl tRNAs, MA_RS23925 and MA_RS23930, suggesting that MA_RS23910 may function as a methionyl-tRNA formyltransferase. A crippled methionyl-tRNA formyltransferase would seem to fit the NB89 phenotype if reduced enzyme activity was enough to satisfy the growth rate on acetate, but was not fast enough to satisfy a faster growth rate on methanol. To directly determine which of these mutations causes the growth defect of the NB89 strain it will be necessary to recreate the mutations and rescue the mutant phenotype by complementation.

Several mutations in bona fide methanogenesis genes or promoters were recovered in the mutant strains. Specifically NB93 has mutations in the methyl-coenzyme M mor promoter and in the acetyl-CoA synthase/decarbonylase synthase promoter, NB181 has a frame shift in $\mathrm{F}_{420} \mathrm{H}_{2}$ :methanophenazine oxidoreductase $f p o L$ subunit, NB193 has a mutation in the $m t s F$ methyltransferase promoter, and NB194 has a mutation that results in truncation in the $m t b C 1$ corrinoid protein. The mutations found in each of the sequenced strains are shown in Figures S1-S8 and summarized in Table S4.

Many of the mutations detected were found in TT-rich regions such as intergenic terminators and promoters, and repeat regions within coding sequences. This is consistent with the mechanism of UVinduced mutagenesis (pyrimidine dimers) and repair by the non-homologous end-joining (NHEJ) DNA repair pathway (40). Therefore the amount and duration of DNA exposure affects the types of mutations recovered and must be experimentally titrated. For instance, excess UV irradiation would be expected to result in numerous severe indel mutations, such as we observed in strain NB195. Strain NB195 had 84 bases inserted at position 273884 (MA_RS11545), four insertions of the same 39 base sequence and six missense mutations in MA_RS1575, and three other deletions at positions 3958294, 4562039, and 5643060. In contrast, strain NB178 had only four point mutations and one insertion at an intergenic repeat region at position 3345530 . 


\section{Struvite formation on acetate}

When collecting tertiary screening data in Balch tubes, NB89 and three other strains were observed to produce crystals during growth on acetate. Crystals were large, between 2-6 mm in length, and rhombic (Figure 5A). Small crystals are occasionally observed in parent strain culture tubes when settled, stationary-phase cultures are left on the benchtop for weeks (as might occur after an experiment is completed but before Balch tubes are cleaned). The crystals we observed in the mutant strains were different, however, because of the size, ordered structure, and speed of crystal formation. Crystals began to form as mutant cultures entered late exponential phase, and were reproducible. The acetate crystal phenotype appeared to be heritable when cells were passaged to fresh acetate medium, and when they were switched to methanol medium and back to acetate medium. Crystals were not observed in all mutants, nor were they observed in parent cultures.

Figure 5. Acetate-dependent struvite formation. A, Balch tube showing large rhombic struvite crystals (black arrows). B, Scanning electron microscopy of struvite crystals (bar $=10 \mu \mathrm{m}$ ). C and D, Biological material suggestive of a biofilm (C) or adhered cells (D) were observed on crystal surfaces (bar $=1 \mu \mathrm{m}$ ). E, X-ray powder diffraction spectra of crystals.

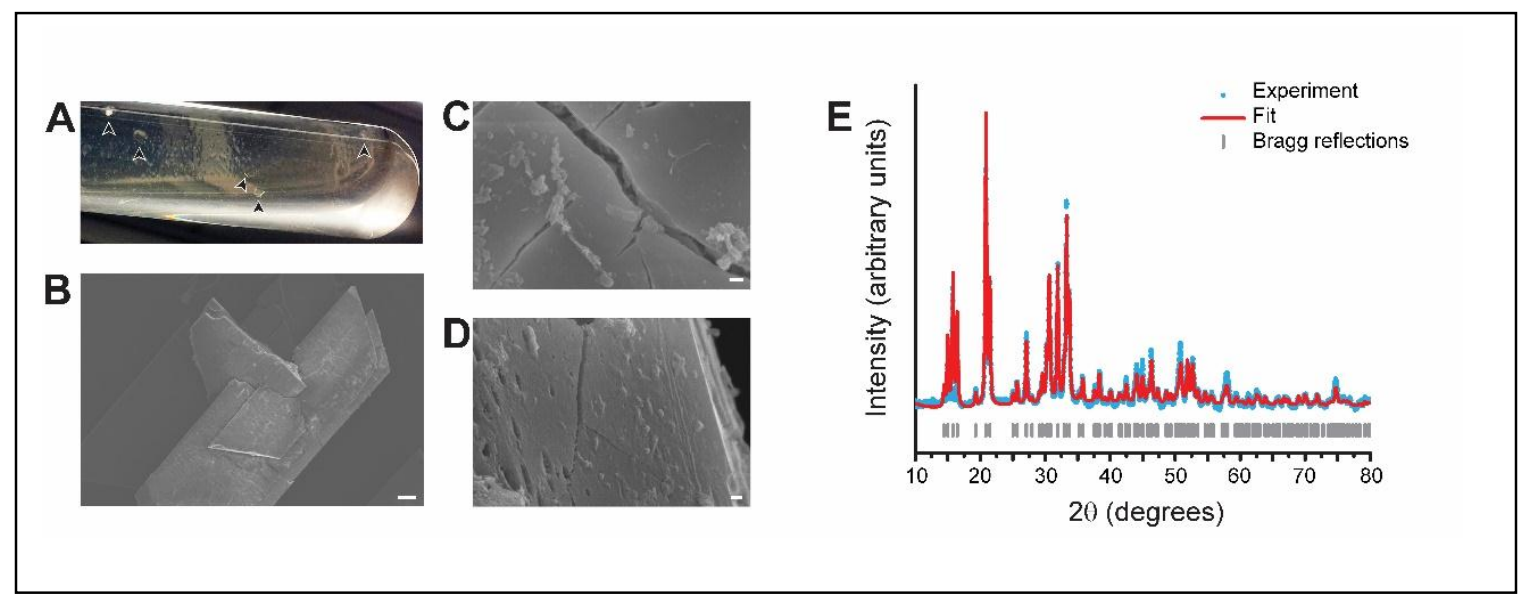

We collected the crystals and tested their ability to dissolve in acid. The crystals were air-stable, and dissolved slowly in cold $0.1 \mathrm{M} \mathrm{HCl}$, indicating they were not composed of carbonate. We observed crystal morphology by scanning electron microscopy (Figure 5B-D). Though cells, or perhaps biofilm, were 
observed on the surface of the crystals, the crystal faces were generally smooth, and it did not appear as if cells were trapped within the crystals. Crystal composition was identified using powder x-ray diffraction. The XRD spectra was characteristic of the mineral $\left(\mathrm{NH}_{4}\right) \mathrm{Mg}\left(\mathrm{PO}_{4}\right)\left(\mathrm{H}_{2} \mathrm{O}\right)_{6}$, otherwise known as struvite (Figure 5E). The microscopy and XRD data therefore suggest the mutant strains catalyze struvite mineralization by increasing the $\mathrm{pH}$ of the medium beyond the bicarbonate/ $\mathrm{KPO}_{4}$ buffering capacity.

\section{Discussion}

\section{Method evaluation}

A forward genetics approach has the potential to identify every gene that is involved in expression of a phenotype. In the method described, UV mutagenesis was selected as an inexpensive, universally applicable mutagenesis method. Other forward genetics methods employ chemical mutagens or transposable elements, which have their own strengths and weaknesses $(13,41-45)$. A particular organism may or may not be sensitive to a particular chemical mutagen, or the cells may have extracellular structures (capsule, hydrophobic pellicle, cell wall structures, etc.) or biochemical detoxification mechanisms ( $\mathrm{P}_{450}$-type enzymes) that may pose a barrier for mutagen uptake or sensitivity. Transposon mutagenesis requires a method for efficient delivery of DNA into cells, either by transformation/transfection, conjugation, or phage/virus infection. In addition, some transposons favor insertion "hot spots", which may result in over-representation of some recovered mutants and underrepresentation of others $(22,46,47)$.

UV mutagenesis generates point mutations across the entire genome, which can result in nonsense or frame-shift mutations in either the promoter (or other cis-regulatory elements) or in the gene reading frame. The degree of phenotype change is a function of how severe the mutation is, ranging from having a subtle effect on transcription/translation, to complete gene loss due to a translational frame shift. One major difficulty with a forward genetics approach is identifying the mutation on the chromosome.

Platforms such as the Illumina MySeq are ideally suited for detection of single-nucleotide polymorphisms, which are easily mapped against a genome sequence. A read depth of 20,000x coverage is generally sufficient for identifying mutations derived from the initial UV mutagenesis event that have become fixed in the culture population. Forward genetics is more experimentally involved and initially expensive than reverse genetics, however, for organisms that lack an efficient genetic system and/or have a relatively high proportion of unknown genes (such as in phylogenetically deep-branching 
microbes), forward genetics makes it possible to begin to link genes and transcripts to systems-level phenotypic functions.

While several methanogen species are genetically tractable, many genes remain uncharacterized, and there are likely many genes of unknown function that play a role in growth and methane production. In M. acetivorans, acetoclastic methanogenesis is thought to involve 303 genes (by microarray) or 257 genes (by proteomics), and methylotrophic methanogenesis involves 407 genes (by microarray) and 441 genes (by proteomics), for an overall range of 664 to 774 genes which are specifically involved in either pathway, or roughly $13.8 \%$ to $16.1 \%$ of genome (48-50). Therefore, the probability of finding a mutation in either acetoclastic or methylotrophic pathways is $4.4 \times 10^{-4}$ under the conditions we describe.

For full saturation mutagenesis of the $5.75 \mathrm{Mb}$ M. acetivorans genome with 4807 genes, we should screen approximately 10,000 colonies (51). Assuming a single mutation per colony (the actual number of mutations per chromosome will follow a Poisson distribution and vary depending on mutagenesis conditions), we sampled up to $20 \%$ of the genome. Theoretically, we mutated between 133-154 genes in either the acetoclastic or methylotrophic pathways, and we picked 133 colonies, $13.9 \%$, that appeared to have slow or fast growth from the primary screen, in close agreement with the theoretical number predicted from transcriptomics and proteomics. After secondary and tertiary screening, the number of confirmed mutants dropped to 10 , and may have resulted from human error when transferring cells from 96-well plates to Balch tubes, may reflect the change in growth conditions between 96-well plates and Balch tubes, or may be a consequence of selection for suppressor or reversion mutants upon subculturing.

Finally, we note that genome copies can affect the efficiency of forward genetic screens. Prokaryotes, and methanogens in particular, may have more than one copy of the genome. Multiple genome copies can serve as templates for DNA repair by homologous recombination. For instance, when M. acetivorans grows on methanol, each cell contains 16 copies of the genome $(52,53)$. In order to recover stable mutant strains, all copies of the genome must contain the mutation. If a mutation in one of sixteen gene copies causes a decrease in fitness, it is only a matter of a few generations before the genome copies segregate, homologous recombination replaces the defective lesion, and the population genotype is converted back to the most-fit allele. Therefore initial selection of single colonies under permissive conditions is critical for maximizing the chance for obtaining strains that will exhibit mutant phenotypes under an alternative (or stressed) growth condition. 


\section{Struvite formation can be stimulated by chromosomal mutations.}

We were intrigued that several of the mutants produced struvite crystals. Struvite can precipitate abiotically at alkaline $\mathrm{pH}$ when phosphate and ammonium concentrations are high. Our observation that struvite formation was reproducible, heritable, and constrained to acetoclastic growth suggests these mutants have mutations that increase nitrogen fixation, have increased $\mathrm{CO}_{2}$ fixation, or increased proton transport into the cell. Any alteration in these metabolic activities would be expected to tip the balance of conditions towards favoring struvite formation.

There is no current evidence directly linking methanogens with struvite mineral precipitation. However, struvite precipitation is common in anoxic environments inhabited by methanogens. For instance, struvite formation is used in municipal water treatment facilities to capture phosphate and ammonia (54-56). However, struvite can build up in the sediment within pipes carrying anoxic, untreated waste, eventually clogging them. Clearing struvite requires removal and replacement of the obstructed sections, at considerable cost.

Struvite can also form in biological tissues, forming kidney stones, gall bladder stones, and encrusting catheters. Oxalate-producing pathogenic bacteria are known to be associated with kidney and urinary endoliths comprised of oxalate, but there is evidence that some patients may present non-oxalate struvite endoliths that are not associated with bacterial infection (57). Struvite endoliths also cause significant morbidity in some breeds of canines and equines, where they are more commonly found in the colon (58). In the human colon, struvite (non-oxalate) endoliths are associated with Crohn's disease and diverticulitis, diseases which are also linked to perturbations in the methanogen population of the gut microbiome (58-62). Further research is needed to determine if and how methanogens may contribute to altering production of organic acids, $\mathrm{CO}_{2}$ and/or ammonia by the microbiome to contribute to struvite endolith formation in vivo. 


\section{Acknowledgements}

The authors would like to thank Shah Valloppilly in the Nebraska Center for Nanomaterials Research for help with X-ray diffraction.

\section{Funding}

This work was supported by National Science Foundation grant IOS-1449525 to NRB and by the Nebraska Tobacco Settlement Biomedical Research Development Funds. Any opinions, findings, and conclusions or recommendations expressed in this material are those of the author(s) and do not necessarily reflect the views of the funding agencies.

\section{References cited}

1. Schierenbeck L, Ries D, Rogge K, Grewe S, Weisshaar B, Kruse O. 2015. Fast forward genetics to identify mutations causing a high light tolerant phenotype in Chlamydomonas reinhardtii by whole-genome-sequencing. BMC Genomics 16:57, 10.1186/s12864-015-1232-y.

2. Farrell A, Coleman BI, Benenati B, Brown KM, Blader IJ, Marth GT, Gubbels MJ. 2014. Whole genome profiling of spontaneous and chemically induced mutations in Toxoplasma gondii. BMC Genomics 15:354, 10.1186/1471-2164-15-354.

3. Nguyen BD, Valdivia RH. 2013. Forward Genetic Approaches in Chlamydia trachomatis. Jove-J Vis Exp.

4. Faivre D, Baumgartner J. 2015. The Combination of Random Mutagenesis and Sequencing Highlight the Role of Unexpected Genes in an Intractable Organism. Plos Genetics 11.

5. Harper MA, Chen Z, Toy T, Machado IM, Nelson SF, Liao JC, Lee CJ. 2011. Phenotype sequencing: identifying the genes that cause a phenotype directly from pooled sequencing of independent mutants. PLoS One 6:e16517, 10.1371/journal.pone.0016517.

6. Sowers KR, Baron SF, Ferry JG. 1984. Methanosarcina acetivorans sp. nov., an Acetotrophic Methane-Producing Bacterium Isolated from Marine Sediments. Appl Environ Microbiol 47:971978.

7. Galagan JE, Nusbaum C, Roy A, Endrizzi MG, Macdonald P, FitzHugh W, Calvo S, Engels R, Smirnov S, Atnoor D, Brown A, Allen N, Naylor J, Stange-Thomann N, DeArellano K, Johnson R, Linton L, McEwan P, McKernan K, Talamas J, Tirrell A, Ye W, Zimmer A, Barber RD, Cann I, Graham DE, Grahame DA, Guss AM, Hedderich R, Ingram-Smith C, Kuettner HC, Krzycki JA, Leigh JA, Li W, Liu J, Mukhopadhyay B, Reeve JN, Smith K, Springer TA, Umayam LA, White O, White RH, Conway de Macario E, Ferry JG, Jarrell KF, Jing H, Macario AJ, Paulsen I, Pritchett M, Sowers KR, Swanson RV, Zinder SH, Lander E, Metcalf WW, Birren B. 2002. The genome of $M$. acetivorans reveals extensive metabolic and physiological diversity. Genome Res 12:532-542, 10.1101/gr.223902.

8. Markowitz VM, Chen IM, Palaniappan K, Chu K, Szeto E, Pillay M, Ratner A, Huang J, Woyke T, Huntemann M, Anderson I, Billis K, Varghese N, Mavromatis K, Pati A, Ivanova NN, Kyrpides 
NC. 2014. IMG 4 version of the integrated microbial genomes comparative analysis system. Nucleic Acids Res 42:D560-567, 10.1093/nar/gkt963.

9. Buan N, Kulkarni G, Metcalf W. 2011. Genetic methods for Methanosarcina species. Methods Enzymol 494:23-42, 10.1016/B978-0-12-385112-3.00002-0.

10. Metcalf WW, Zhang JK, Wolfe RS. 1998. An anaerobic, intrachamber incubator for growth of Methanosarcina spp. on methanol-containing solid media. Appl Environ Microbiol 64:768-770.

11. Horne AJ, Lessner DJ. 2013. Assessment of the oxidant tolerance of Methanosarcina acetivorans. FEMS Microbiol Lett 343:13-19, 10.1111/1574-6968.12115.

12. Metcalf WW, Zhang JK, Shi X, Wolfe RS. 1996. Molecular, genetic, and biochemical characterization of the serC gene of Methanosarcina barkeri Fusaro. J Bacteriol 178:5797-5802.

13. Guss AM, Rother M, Zhang JK, Kulkarni G, Metcalf WW. 2008. New methods for tightly regulated gene expression and highly efficient chromosomal integration of cloned genes for Methanosarcina species. Archaea 2:193-203.

14. Martin M. 2011. Cutadapt removes adapter sequences from high-throughput sequencing reads. 2011 17, 10.14806/ej.17.1.200 pp. 10-12.

15. Edgar RC. 2010. Search and clustering orders of magnitude faster than BLAST. Bioinformatics 26:2460-2461, 10.1093/bioinformatics/btq461.

16. Li H, Durbin R. 2009. Fast and accurate short read alignment with Burrows-Wheeler transform. Bioinformatics 25:1754-1760, 10.1093/bioinformatics/btp324.

17. Li H. 2011. A statistical framework for SNP calling, mutation discovery, association mapping and population genetical parameter estimation from sequencing data. Bioinformatics 27:2987-2993, 10.1093/bioinformatics/btr509.

18. Institute B, posting date. Picard. [Online.]

19. Quinlan AR, Hall IM. 2010. BEDTools: a flexible suite of utilities for comparing genomic features. Bioinformatics 26:841-842, 10.1093/bioinformatics/btq033.

20. Manna D, Wang X, Higgins NP. 2001. Mu and IS1 transpositions exhibit strong orientation bias at the Escherichia coli bgl locus. J Bacteriol 183:3328-3335, 10.1128/JB.183.11.3328-3335.2001.

21. Mullany P, Wilks M, Tabaqchali S. 1991. Transfer of Tn916 and Tn916 $\Delta \mathrm{E}$ into Clostridium difficile: demonstration of a hot-spot for these elements in the $C$. difficile genome. FEMS Microbiol Lett 63:191-194.

22. Lee SY, Butler D, Kleckner N. 1987. Efficient Tn10 transposition into a DNA insertion hot spot in vivo requires the 5-methyl groups of symmetrically disposed thymines within the hot-spot consensus sequence. Proc Natl Acad Sci U S A 84:7876-7880.

23. Witkin EM. 1976. Ultraviolet mutagenesis and inducible DNA repair in Escherichia coli. Bacteriol Rev 40:869-907.

24. Hartmann E, Konig H. 1991. Nucleotide-activated oligosaccharides are intermediates of the cell wall polysaccharide of Methanosarcina barkeri. Biol Chem Hoppe Seyler 372:971-974.

25. Sowers KR, Gunsalus RP. 1988. Adaptation for growth at various saline concentrations by the archaebacterium Methanosarcina thermophila. J Bacteriol 170:998-1002.

26. Steber J, Schleifer KH. 1975. Halococcus morrhuae: a sulfated heteropolysaccharide as the structural component of the bacterial cell wall. Arch Microbiol 105:173-177.

27. Klingl A. 2014. S-layer and cytoplasmic membrane - exceptions from the typical archaeal cell wall with a focus on double membranes. Front Microbiol 5:624, 10.3389/fmicb.2014.00624.

28. Rohlin L, Leon DR, Kim U, Loo JA, Ogorzalek Loo RR, Gunsalus RP. 2012. Identification of the major expressed S-layer and cell surface-layer-related proteins in the model methanogenic archaea: Methanosarcina barkeri Fusaro and Methanosarcina acetivorans C2A. Archaea 2012:873589, 10.1155/2012/873589. 
29. Francoleon DR, Boontheung P, Yang Y, Kin U, Ytterberg AJ, Denny PA, Denny PC, Loo JA, Gunsalus RP, Loo RR. 2009. S-layer, surface-accessible, and concanavalin A binding proteins of Methanosarcina acetivorans and Methanosarcina mazei. J Proteome Res 8:1972-1982, 10.1021/pr800923e.

30. Namboori SC, Graham DE. 2008. Acetamido sugar biosynthesis in the Euryarchaea. J Bacteriol 190:2987-2996, 10.1128/JB.01970-07.

31. Karcher U, Schroder H, Haslinger E, Allmaier G, Schreiner R, Wieland F, Haselbeck A, Konig H. 1993. Primary structure of the heterosaccharide of the surface glycoprotein of Methanothermus fervidus. J Biol Chem 268:26821-26826.

32. Firtel M, Southam G, Harauz G, Beveridge TJ. 1993. Characterization of the cell wall of the sheathed methanogen Methanospirillum hungatei GP1 as an S layer. J Bacteriol 175:7550-7560.

33. Mengele R, Sumper M. 1992. Drastic differences in glycosylation of related S-layer glycoproteins from moderate and extreme halophiles. J Biol Chem 267:8182-8185.

34. Zellner G, Stackebrandt E, Messner P, Tindall BJ, Conway de Macario E, Kneifel H, Sleytr UB, Winter J. 1989. Methanocorpusculaceae fam. nov., represented by Methanocorpusculum parvum, Methanocorpusculum sinense spec. nov. and Methanocorpusculum bavaricum spec. nov. Arch Microbiol 151:381-390.

35. Conway de Macario E, Konig H, Macario AJ, Kandler O. 1984. Six antigenic determinants in the surface layer of the archaebacterium Methanococcus vannielii revealed by monoclonal antibodies. J Immunol 132:883-887.

36. Mountfort DO, Asher RA. 1979. Effect of inorganic sulfide on the growth and metabolism of Methanosarcina barkeri strain DM. Appl Environ Microbiol 37:670-675.

37. Buan NR, Metcalf WW. 2010. Methanogenesis by Methanosarcina acetivorans involves two structurally and functionally distinct classes of heterodisulfide reductase. Mol Microbiol 75:843853, 10.1111/j.1365-2958.2009.06990.x MMI6990.

38. Guss AM, Kulkarni G, Metcalf WW. 2009. Differences in hydrogenase gene expression between Methanosarcina acetivorans and Methanosarcina barkeri. J Bacteriol 191:2826-2833, JB.0056308 10.1128/JB.00563-08.

39. Jasso-Chavez R, Apolinario EE, Sowers KR, Ferry JG. 2013. MrpA functions in energy conversion during acetate-dependent growth of Methanosarcina acetivorans. J Bacteriol 195:3987-3994, 10.1128/JB.00581-13.

40. Blackwood JK, Rzechorzek NJ, Bray SM, Maman JD, Pellegrini L, Robinson NP. 2013. Endresection at DNA double-strand breaks in the three domains of life. Biochem Soc Trans 41:314320, 10.1042/BST20120307.

41. Sarmiento F, Ellison CK, Whitman WB. 2013. Genetic confirmation of the role of sulfopyruvate decarboxylase in coenzyme $\mathrm{M}$ biosynthesis in Methanococcus maripaludis. Archaea 2013:185250, 10.1155/2013/185250.

42. Sattler C, Wolf S, Fersch J, Goetz S, Rother M. 2013. Random mutagenesis identifies factors involved in formate-dependent growth of the methanogenic archaeon Methanococcus maripaludis. Mol Genet Genomics 288:413-424, 10.1007/s00438-013-0756-6.

43. Rother M, Sattler C, Stock T. 2011. Studying gene regulation in methanogenic archaea. Methods Enzymol 494:91-110, 10.1016/B978-0-12-385112-3.00005-6.

44. Pritchett MA, Metcalf WW. 2005. Genetic, physiological and biochemical characterization of multiple methanol methyltransferase isozymes in Methanosarcina acetivorans C2A. Mol Microbiol 56:1183-1194, MMI4616 10.1111/j.1365-2958.2005.04616.x.

45. Zhang JK, Pritchett MA, Lampe DJ, Robertson HM, Metcalf WW. 2000. In vivo transposon mutagenesis of the methanogenic archaeon Methanosarcina acetivorans C2A using a modified 
version of the insect mariner-family transposable element Himar1. Proc Natl Acad Sci U S A 97:9665-9670, 10.1073/pnas.160272597.

46. Gamas P, Chandler MG, Prentki P, Galas DJ. 1987. Escherichia coli integration host factor binds specifically to the ends of the insertion sequence IS1 and to its major insertion hot-spot in pBR322. J Mol Biol 195:261-272, 0022-2836(87)90648-6 [pii].

47. Wang H, Smith MC, Mullany P. 2006. The conjugative transposon Tn5397 has a strong preference for integration into its Clostridium difficile target site. J Bacteriol 188:4871-4878, 188/13/4871 10.1128/JB.00210-06.

48. Li L, Li Q, Rohlin L, Kim U, Salmon K, Rejtar T, Gunsalus RP, Karger BL, Ferry JG. 2007. Quantitative proteomic and microarray analysis of the archaeon Methanosarcina acetivorans grown with acetate versus methanol. J Proteome Res 6:759-771, 10.1021/pr060383.

49. Li Q, Li L, Rejtar T, Karger BL, Ferry JG. 2005. Proteome of Methanosarcina acetivorans Part II: comparison of protein levels in acetate- and methanol-grown cells. J Proteome Res 4:129-135, 10.1021/pr049831k.

50. Li Q, Li L, Rejtar T, Karger BL, Ferry JG. 2005. Proteome of Methanosarcina acetivorans Part I: an expanded view of the biology of the cell. J Proteome Res 4:112-128, 10.1021/pr049832c.

51. Phogat SK, Gupta R, Burma PK, Sen K, Pental D. 2001. On the estimation of number of events required for saturation mutagenesis of large genomes. Curr Sci India 80:823-824.

52. Soppa J. 2011. Ploidy and gene conversion in Archaea. Biochem Soc Trans 39:150-154, 10.1042/BST0390150.

53. Hildenbrand C, Stock T, Lange C, Rother M, Soppa J. 2011. Genome copy numbers and gene conversion in methanogenic archaea. J Bacteriol 193:734-743, 10.1128/JB.01016-10.

54. Doyle JD, Parsons SA. 2002. Struvite formation, control and recovery. Water Res 36:3925-3940, S0043-1354(02)00126-4.

55. Miles A, Ellis TG. 2001. Struvite precipitation potential for nutrient recovery from anaerobically treated wastes. Water Sci Technol 43:259-266.

56. Scott WD, Wrigley TJ, Webb KM. 1991. A computer model of struvite solution chemistry. Talanta 38:889-895, 0039-9140(91)80268-5.

57. Rodman JS. 1999. Struvite stones. Nephron 81 Suppl 1:50-59, nef1a050.

58. Hassel DM, Schiffman PS, Snyder JR. 2001. Petrographic and geochemic evaluation of equine enteroliths. Am J Vet Res 62:350-358.

59. Hassel DM, Spier SJ, Aldridge BM, Watnick M, Argenzio RA, Snyder JR. 2009. Influence of diet and water supply on mineral content and $\mathrm{pH}$ within the large intestine of horses with enterolithiasis. Vet J 182:44-49, 10.1016/j.tvjl.2008.05.016.

60. Chou YH, Chiou HJ, Tiu CM, Chen JD, Hsu CC, Lee CH, Lui WY, Hung GS, Yu C. 2001. Sonography of acute right side colonic diverticulitis. Am J Surg 181:122-127, S0002-9610(00)00568-7 [pii].

61. Lomhoff, II, Dubowy J. 1948. Gallstone ileus associated with diverticulitis of the colon; a case report. Am J Roentgenol Radium Ther 60:86-89.

62. Harris LM, Volpe CM, Doerr RJ. 1997. Small bowel obstruction secondary to enterolith impaction complicating jejunal diverticulitis. Am J Gastroenterol 92:1538-1540. 